\title{
Actuating Food Residual Detection Habit Using Self-Made Disclosing Agent Solution to Improve the Dental Hygiene for Fertile Age Mothers
}

\author{
Aryo Dwipo Kusumo, Taufan Bramantoro, Titiek Berniyanti, Gilang Rasuna Sabdho Wening, Agung Sosiawan, Retno Palupi \\ Department of Dental Public Health, Faculty of Dental Medicine, Universitas Airlangga, Surabaya, Indonesia
}

\section{Abstract}

Background: Based on the results of the preliminary research on mothers with fertile age couple, 56 people with a percentage of $65.9 \%$ had bad Simplified Oral Hygiene Index of the total sample of 85 people. Aims: This empowerment program aimed to provide counseling to mothers in the village; hence, they could find the benefits of disclosing agent and could make a disclosing agent and could detect dental plaque by using the disclosing agent. Subjects and Methods: This descriptive, analytical study conducted with 85 participants. Participants are given the theory of disclosing agents, practical demonstration, and evaluation how to make disclosing agent themselves. This research was quasi/ experimental design approach, and statistical analysis software used IBM SPSS Statistic 25 (SPSS Inc., Chicago, IL, USA). Results: Participants could find the benefits of the disclosing agent, could make a disclosing agent, and could detect dental plaque by using the disclosing agent. Conclusions: Empowerment program ran well and conducive. Participants could understand the benefits of the disclosing agents. This can be seen from the enthusiasm of the fertile age mothers in paying attention to the material.

Keywords: Disclosing agent, empowerment program, oral hygiene status

\section{INTRODUCTION}

Dental caries is an important health problem because it can affect anyone regardless of age and if it is continued, it will be a focal source of infection in the mouth causing pain complaints. Dental caries disease is caused by low dental and oral hygiene. ${ }^{[1]} \mathrm{Bad}$ dental hygiene has a high risk of caries and vice versa. ${ }^{[2]}$ Dental plaque plays an important role in causing caries. Plaque is a soft layer composed of a collection of microorganisms that multiply above a matrix that is formed and firmly attached to the surface of the untreated tooth. The composition of microorganisms in plaque is different.

Oral health is extremely important for the general well-being of an individual. It is established that there is a definitive connection between periodontal health and many systemic diseases such as type II diabetes mellitus, cardiovascular disease, and even preterm labor and low birth weight of

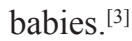

Based on the results of the research on the mothers in fertile age of Trawas Sub-district, Indonesia, there were 56 people

\begin{tabular}{|l|l|}
\hline \multicolumn{2}{|c|}{ Access this article online } \\
\hline Quick Response Code: & Website: \\
\hline & www.jioh.org \\
\hline & \\
\hline
\end{tabular}

with percentage of $65.9 \%$ having bad Simplified Oral Hygiene Index from a total sample of 85 people [Table 1]. This can be due to poor dental and mouth-cleaning behavior which will affect the number of caries occurrence. In addition to poor dental and oral-cleaning behavior, tooth-brushing behavior also affects oral hygiene. The way that is considered effective in dental health care is to brush the teeth so that food scraps and plaque on the surface of the teeth can be cleaned. ${ }^{[4]}$ All oral cavities should be brushed properly so that no areas are still accumulated by plaque. Brush pressure should not be too weak so that the teeth can be cleaned properly. ${ }^{[5]}$

To find whether the remaining food is still attached to the teeth or not, the disclosing agent can be used. ${ }^{[6]}$ Disclosing agent is a colored liquid that serves to detect the remaining food attached to the teeth.

\section{Address for correspondence: Dr. Taufan Bramantoro, JI. Prof Dr. Moestopo, No. 47, Surabaya, Indonesia. E-mail: aryo.dk.dunk@gmail.com}

This is an open access journal, and articles are distributed under the terms of the Creative Commons Attribution-NonCommercial-ShareAlike 4.0 License, which allows others to remix, tweak, and build upon the work non-commercially, as long as appropriate credit is given and the new creations are licensed under the identical terms.

For reprints contact: reprints@medknow.com

How to cite this article: Kusumo $\mathrm{AD}$, Bramantoro $\mathrm{T}$, Berniyanti $\mathrm{T}$, Wening GR, Sosiawan A, Palupi R. Actuating food residual detection habit using self-made disclosing agent solution to improve the dental hygiene for fertile age mothers. J Int Oral Health 2019;11:33-5. 


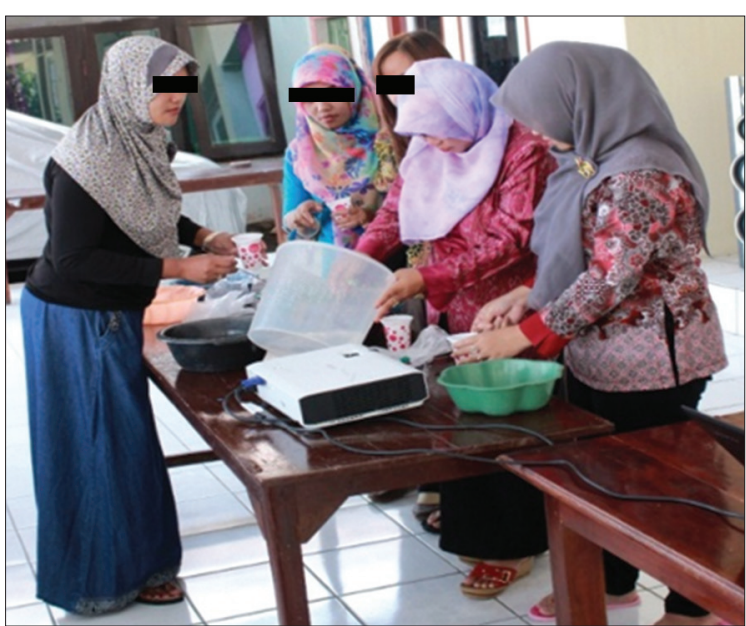

Figure 1: Demonstration of the disclosing agent

Table 1: Participants distribution of Decayed, Missing, Filled Teeth and Simplified Oral Hygiene Index score index

\begin{tabular}{cc}
\hline Risk factor & Frequency, $\boldsymbol{n}(\%)$ \\
\hline DMF-T & \\
$<6$ & $29(34.1)$ \\
$\geq 6$ & $46(65.9)$ \\
OHI-S & \\
$<3$ & $27(31.8)$ \\
$\geq 3$ & $58(62.8)$ \\
\hline
\end{tabular}

$n$ : Number of respondents. DMF-T: Decayed, Missing, Filled Teeth, OHI-S: Simplified Oral Hygiene Index

\section{Subjects and Methods}

The sampling used the total sampling which conducted to 85 participants from mothers with fertile age couple, aged $20-35$, in the village. All the procedures done in this empowerment have been approved by the Health Research Ethical Committee of Airlangga University Dentistry Faculty with letter number 202/KKEPK.FKG/XII/2013. As an objective of the research, after having informed about the objective, procedure, benefits, and confidentiality of the research, respondents have filled the informed consent, and all the procedures have been approved the Committee.

Empowerment was given in the form of demo of making the disclosing agent. This program was implemented in conjunction with other empowerment programs.

1. Introduction to the benefits of using the disclosing agent

2. Demo of making the disclosing agent was then conducted

3. Counseling the importance of brushing the teeth on all surfaces

4. Evaluation.

Respondents were given materials about dental and oral health, as well as how to do prevention and simple treatments that can be done at home. An example is getting used to using mouthwash. After giving the materials about the benefits and understanding of mouthwash, respondents were trained to be able to make their own mouthwash. After

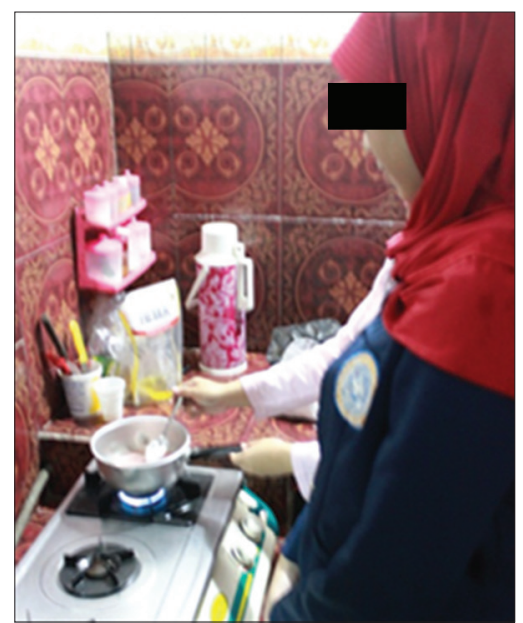

Figure 2: Making disclosing agent at home

the demonstration of making mouthwash, an evaluation of the materials that have been delivered in the hope that the respondents will disseminate the knowledge received to those around them.

\section{RESULTS}

Before the demo disclosing agent, the participants did not understand the benefits and how to make the disclosing agent. After a demonstration on how to make a disclosing (agent as shown in the Figure 1), the participants could make their own disclosing agent with food coloring and understand its benefits [Figure 2]. With this empowerment program, the participants were able to demonstrate their own disclosing agent and to educate how to create disclose agent to their families and people.

\section{Discussion}

Respondents seemed enthusiastic about participating in the activities held. They listened carefully to the explanation and counseling on dental and oral health, also practiced well when asked to demonstrate how to brush teeth properly and correctly. Compared to the method used previously (counseling and question and answer), the practice method of making mouthwash is more attractive to the respondents because there are activities that stimulate their enthusiasm and interest. Self-made disclosing agent training is aimed to develop the personal skill of the participants, who are the fertile age mothers. This kind of activity helps participants to enjoy and easier for them to received dental health education. Food residual detection is the simplest way to know whether their mouth is clean or not. By actuating the residual food detection habit, we hope that this program can improve the oral hygiene of the participants.

Health promotion is not a new idea if one takes it to mean any or all activities that improve the health of individuals and communities. ${ }^{[7]}$ The general strategies and approaches required to successfully confront the deterioration of global health 
status are well known. These include five primary strategies for health promotion which are as follows: build healthy public policy, create supportive environment, strengthen community action, develop personal skill, and reorient health service. ${ }^{[8]}$ It is expected that respondents can make their own mouthwash and apply the habit of gargling after eating, using normal water or homemade mouthwash. As a result, people in this research area will become independent in making mouthwash and continue this good habit.

In a developing country, health problems are increasing drastically. This is caused by the lack of knowledge given to the society about the dental and oral health and also the enthusiasm of people itself. That is why we need an empowerment program to initiate and improve the concern about the dental and oral health. Moreover, the mothers in fertile age is one of the important targets to be given empowerment that support the community group organization and action on health determinants. ${ }^{[9,10]}$

Limitation of this study was only using demonstration evaluating method. For future research, the researcher can compare the effectiveness of herbal mouthwash and branded mouthwash sold in the public.

\section{Conclusion}

Empowerment program ran well and conducive. Participants could understand the benefits of disclosing agents. This can be seen from the enthusiasm of the fertile age mothers in paying attention to the material.

\section{Declaration of patient consent}

The authors certify that they have obtained all appropriate patient consent forms. In the form the patient(s) has/have given his/her/their consent for his/her/their images and other clinical information to be reported in the journal. The patients understand that their names and initials will not be published and due efforts will be made to conceal their identity, but anonymity cannot be guaranteed.

\section{Acknowledgment}

This study was acknowledged by the Department of Dental Public Health, Faculty of Dentistry, Universitas Airlangga.

\section{Financial support and sponsorship}

Nil.

\section{Conflicts of interest}

There are no conflicts of interest.

\section{RefEREnCES}

1. John JR, Daniel B, Paneerselvam D, Rajendran G. Prevalence of dental caries, oral hygiene knowledge, status, and practices among visually impaired individuals in Chennai, Tamil Nadu. Int J Dent 2017;2017:9419648.

2. Alhamda S. Oral Hygiene Status and Dental Caries Status (study on 12-year-old group students at Bukit Tinggi State Elementary School). Public Health News 2011;27:108-15.

3. Khanna SS, Dhaimade PA, Malhotra S. Oral health status and fertility treatment including IVF. J Obstet Gynaecol India 2017;67:400-4.

4. Damle SG, Patil A, Jain S, Damle D, Chopal N. Effectiveness of supervised toothbrushing and oral health education in improving oral hygiene status and practices of urban and rural school children: A comparative study. J Int Soc Prev Community Dent 2014;4:175-81.

5. Newman MG, Takei H, Klokkevold PR, Carranza FE. Carranza's Clinical Periodontology. 13 ${ }^{\text {th }}$ ed. Philadelphia, PA:Elsevie; 2018. p. 237.

6. Sumawinata N. Manual Restorative Conservation According to Pickard. $6^{\text {th }}$ ed. Jakarta: Widya Medika; 2004. p. 6-8.

7. Laverack G. Health Promotion Practice: Power and Empowerment. London: Sage Publication; 2004.

8. Bracht N. Health Promotion at the Community Level 2. London: Sage Publication; 1999.

9. Labonte R, Laverack G. Health Promotion in Action. England: Palgrave Macmillan; 2008.

10. Labonte R. Health public policy and the World Trade Organization: A proposal for an international health presence in future World Trade/ Investment Talk. Health Promot Int 1998;13:245-56. 